
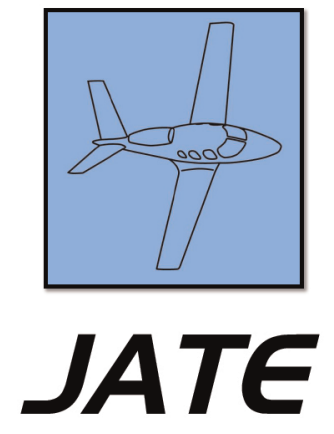

Journal of Aviation Technology and Engineering 2:1 (2012) 125-129

DOI: $10.5703 / 1288284314864$

\title{
The Dunning-Kruger Effect and SIUC University's Aviation Students
}

\author{
Samuel R. Pavel, Michael F. Robertson and Bryan T. Harrison \\ Southern Illinois University Carbondale
}

\begin{abstract}
This paper describes a two-part study on the Dunning-Kruger effect in SIUC University's aviation students. The Dunning-Kruger effect indicates that individuals with lower skill or knowledge levels have unrealistic positive images of their capabilities compared to their peers. Results indicate that the Dunning-Kruger effect is present in SIUC aviation students. Students scoring lower on both a grammar test and a pilot knowledge test grossly overestimated their ability, while higher scoring students underestimated their ability. Additional research using other pilot training programs and other aviation industry safety personnel should be undertaken before any generalizations can be made. However, this study indicates that the Dunning-Kruger effect might be a problem within the aviation industry and could play a role in the safety of the National Airspace System.
\end{abstract}

Keywords: Dunning-Kruger effect, aviation, overconfidence

\section{Introduction}

Self-perception of ability may not always be based in reality. Overestimation of one's ability in the field of aviation can lead to dire consequences. Some concerning scenarios include a pilot continuing Visual Flight Rules (VFR) flight into Instrument Meteorological Conditions (IMC) without adequate training or proficiency, a pilot transitioning to new aircraft

\footnotetext{
About the Authors

Samuel Pavel is an Assistant Professor at Southern Illinois University Carbondale in the Department of Aviation Management and Flight, fulfilling his lifetime dream of teaching for a major collegiate aviation program. His research interests include aviation history, curriculum and pedagogy, particularly in the areas of air traffic control and aviation management.

Michael Robertson is an Associate Professor in the Department of Aviation Management and Flight, Southern Illinois University Carbondale (SIUC). He has served as the Safety Officer for the Aviation Flight Program since 2007 and possesses a Certified Flight Instructor Certificate with Multi-Engine and Instrument

Bryan Harrison is an assistant professor in the Department of Aviation Management and Flight at Southern Illinois University. His research interests include curriculum development, flight student success factors, and integration of technically advanced aircraft.
} 
or avionics without adequate training, an air traffic controller underestimating how close two aircraft will pass each other, or an A\&P mechanic working on an unfamiliar aircraft or engine. The Dunning-Kruger Effect indicates that individuals with lower skill or knowledge levels have unrealistic positive images of their capabilities when they compare themselves to their peers. Kruger and Dunning (2009) also suggest that the lack of skill or ability itself prevents individuals from knowing the extent of their incompetence. While unskilled individuals tend to overestimate their abilities, the most knowledgeable or skilled individuals often underestimate their abilities.

This two-phase study examines the applicability of the Dunning-Kruger Effect to collegiate aviation students at Southern Illinois University Carbondale (SIUC). Phase one recreated Study 3 of Kruger and Dunning's (2009) research by measuring participating students' perceived performance on a grammar exam both pre-exam and post-exam. Phase two of this study compared participating students' predicted score on a Federal Aviation Administration (FAA) knowledge exam to their actual score.

\section{Literature Review}

The tendency for individuals to evaluate themselves more favorably in comparison to others has been a staple finding in social psychology for many years. This principle has been referred to as the better-than-average effect. The better-than-average effect provides evidence that people, in general, have unrealistic positive images of themselves compared to their peers (Alicke, Klotz, Breitenbecher, Yurak, \& Vredenburg, 1995). Over the years, many studies have been conducted in social psychology concerning the idea of the better-than-average effect (Alicke, 1985; Allison, Messick, \& Goethals, 1989; Codol, 1975; Cross, 1977; Dunning, Meyerowitz, \& Holzberg, 1989; Messick, Bloom, Boldizar, \& Samuelson, 1985). Alicke et al. (1995) conducted seven studies to demonstrate the magnitude of the better-than-average effect. It was determined that the effect depends on the level of abstraction in the comparison. In other words, the better-than-average effect was reduced when the individual had personal contact with the comparison target as opposed to another peer.

In 2009, two Cornell University psychologists, Justin Kruger and David Dunning, published a paper entitled Unskilled and unaware of it: how difficulties in recognizing one's own incompetence lead to inflated self-assessments. Kruger and Dunning identified a tendency for people with relatively lower skill levels and knowledge to overestimate their ability to accomplish a task, whereas people with relatively higher skill levels and knowledge would tend to underestimate their ability to complete a task. The results of this study were so conclusive that this tendency was named after the authors as the Dunning-Kruger Effect.
Kruger and Dunning (2009) conducted four studies focusing on humor, logical reasoning and grammar. They found that participants that scored in the bottom quartile overestimated their performance and ability. More specifically, the participants' test scores put them in the 12th percentile while they perceived themselves to be in the 62nd percentile. Overall, the researchers concluded that people in general tend to be overly optimistic about their skills and abilities. Not only will these individuals reach mistaken conclusions and make errors, but their incompetence does not give them the ability to realize it. They also concluded that the less we know about a particular subject, the less we are able to recognize the expertise of others as it relates to that subject (Kruger \& Dunning, 2009).

Dan Grunloh (2011), editor of Light Plane World, wrote an article regarding how the Dunning-Kruger Effect could be applied to aviation, where the cognitive failure of not being able to recognize one's own lack of knowledge or performance would be of serious concern. Any pilot, whether a newcomer or pilot transitioning from type, could be tricked by this effect. For example, a novice pilot who thinks it is acceptable to minimize maintenance issues or checklists may be suffering from the Dunning-Kruger Effect (Grunloh, 2011).

Casner (2008) conducted a study surveying 134 general aviation pilots exploring topics such as a pilot's general attitudes toward advanced cockpit systems and how pilots believe these systems affect workload and awareness. The survey also explored a pilot's preferences for cockpit systems, a pilot's perceptions of risk, long-term effects on pilot skill and the effects of advanced cockpit systems on the number of errors pilots make as well as the overall safety record. The results of the survey indicated that while most pilots hold generally positive attitudes about advanced cockpit systems and exhibit a strong preference for using them, they also recognize the potential pitfalls associated with advanced cockpit systems but are more likely to attribute the problems to other pilots rather than to themselves. A number of contradictory attitudes from the study pointed out a potential need for future studies to clarify the effect of attitudes and beliefs on pilot behavior and ultimately the effects on safety.

As mentioned previously, the better-than-average effect and the Dunning-Kruger Effect have been used in many studies in social psychology for many years. These studies largely focused on social predictions; other studies have also applied these effects to college students and their ability to predict their performance in college (Everson \& Tobias, 1998). Although little research exists on the Dunning-Kruger Effect in aviation and more specifically collegiate flight training, it seems that based on the previous studies mentioned the Dunning-Kruger Effect is prevalent in college students (Alicke et al., 1995; Everson \& Tobias, 1998; Kruger \& Dunning, 1999) as well as pilots (Casner, 2008). 


\section{Methodology}

This study was conducted in two phases. The first phase was based on Study 3 of the original Kruger and Dunning study (2009). The original Cornell study clearly showed the Dunning-Kruger Effect present in the US collegiate elite. SIUC aviation students generally score above average on the ACT college entrance exam; however, the SIUC aviation student's average ACT score is significantly less than the average Cornell University student's ACT score (Cornell n.d.; Author's calculation from study participants). The purpose of the first phase is to see if the DunningKruger Effect was prevalent in the SIUC aviation students using a grammar exam.

The grammar exam was constructed using ten items that were randomly selected from each of two sections in the National Teachers Exam preparation guide (Bobrow et al., 1989). The first part of the exam consisted of ten sentences. Each sentence had four specific portions underlined. The participants were to choose the underlined portion that was grammatically incorrect, or circle No error. The second part of the exam also consisted of ten sentences. This time only one portion of each sentence was underlined. The participants were to decide if the underlined portion of the sentence was grammatically correct and, if not, choose the grammatically correct answer from a list of four other choices.

Prior to taking the grammar exam, participants were asked to rank their ability to recognize grammatical errors on a scale from one to ten, with one being poor and ten being excellent. The participants were next asked to predict the number of correct answers they would get out of the twenty questions on the exam. The participants then completed the grammar exam. After completing the exam the participants were asked to once again predict the number of correct answers they got on the exam.

From Fall 2010 through Fall 2011, students from five sections of an Aviation Technical Communication course were asked to participate in the study and take the grammar exam. There was no compensation or extra credit offered. Participation was anonymous and voluntary. One hundred and seventeen students agreed to volunteer for the study and 99 students submitted a completed exam and accompanying predictions.

Phase two of the study compared predicted and actual scores on FAA written exams for the Private, Instrument, and Commercial pilot certificates. Prior to taking one of the three exams, students were asked to volunteer for the study and complete a questionnaire. Participation was strictly voluntary with no compensation or extra credit offered. After completing the pre-exam questionnaire and FAA exam, the data was recorded and all identifying information was shredded or deleted so no individual student's information or FAA exam score could be identified.
The pre-exam questionnaire asked students for their age, number of flight hours to date, their ACT score, their perceived pilot skill on a scale of 1 to 10 (with 1 being poor and 10 being excellent), and the score they predicted they would receive on the FAA exam. The test administrator of the FAA exam, with the students' permission, released the actual score on the FAA exam to the researchers. Sixtyseven students participated in phase two of this study from Fall 2010 through Fall 2011.

In both phases of the study the students were divided into quintiles based on their actual scores, and the quintile score was converted to percentiles. Then each quintile's predicted score was compared with the quintile's actual score using a one-sample $\mathrm{t}$ test. This methodology was used to be consistent with the original Cornell study.

When comparing the perceived pilot ability in Phase Two of this study, the small sample size and large variations in the rankings makes precise statistical analysis difficult. The quintile averages follow the trend indicated in the other quintile score comparisons so the averages are reported in the results section; however, more data would be needed to make any conclusive statement.

\section{Results and Discussion}

\section{Phase One: Grammar Exam}

The results of the SIUC Aviation students was similar to the results of the Cornell students in the original study conducted by Kruger and Dunning (2009). In the Cornell study the participants estimated their grammatical ability to be in the 71st percentile on average and their performance on the test to be in the 68th percentile on average, exceeding the actual mean of $50, \mathrm{t}(83)=5.90$ and 5.13 , respectively, $\mathrm{p}<.0001$. The bottom quartile of students grossly overestimated their grammatical ability and perceived score on the grammar exam. Although the actual score of the Cornell students in the bottom quartile was in the 10th percentile on average, they estimated their grammatical ability and predicted scores on the exam to be in the 67th and 61st percentiles respectively, $\mathrm{t}(16)=13.68$ and 15.75, $\mathrm{p}<.0001$. The top quartile of Cornell students underestimated their grammatical ability and perceived scores on the exam. Their actual exam score was in the 89th percentile, however they estimated their grammatical ability and test performance to be in the 72nd and 70th percentile, $\mathrm{t}(18)=-4.73$ and -5.08 , respectively, $\mathrm{p}<.0001$.

The SIUC aviation students followed a pattern similar to that of the Cornell students. The students estimated their grammatical ability at the 66th percentile on average, $\mathrm{t}(98)=9.49, \mathrm{p}<.0001$, and their predicted scores in the 87th percentile on average, $t(98)=10.20, \mathrm{p}<.0001$. Overall the students' perceived grammatical ability and predicted scores are only moderately correlated with the 
actual scores, $\mathrm{t}(99)=.363, \mathrm{p}<.0001$ and $\mathrm{r}(99)=.300$, $\mathrm{p}<.003$, respectively. Not surprisingly, the students' estimate of grammatical ability and predicted scores was strongly correlated, $\mathrm{t}(99)=.713, \mathrm{p}<.0001$.

The bottom quartile of participants scored in the 10th percentile on average. However, they estimated their grammatical ability to be 5.72 on average, and their predicted scores to be in the 68th percentile, $\mathrm{t}(24)=12.57$, $\mathrm{p}<.0001$. The top quintile of participants scored in the 92nd percentile on average. They predicted their grammatical ability at 7.55 on average. However, their predicted scores were almost the same as their actual scores (M percentile $=95$ ).

After taking the grammar exam the students were far less confident in their original predicted scores. Every quartile group lowered their prediction of how they would score on the exam. On average, the lowest two quartiles more accurately predicted their actual scores (M percentile $=47.7, \mathrm{t}(24)=4.17, \mathrm{p}<.0001 ; \mathrm{M}$ percentile $=57$, $\mathrm{t}(24)=1.98, \mathrm{p}<.059$, respectively). The third quartile almost predicted its average actual score ( $M$ percentile $=67.5$ ). Interestingly the top quartile on average underestimated their scores $(\mathrm{M}$ percentile $=82.6$, $\mathrm{t}(23)=-1.82, \mathrm{p}<.082)$.

\section{Phase Two: FAA Exams}

SIUC aviation students showed the same tendencies in their ability to predict their exam results with the FAA exams as they did with the grammar exam. The first item to note is that almost all of the students in the study ranked their pilot skill above 5 on a scale from $1-10$, with an average score of $7.11(S D=1.35)$. The bottom quartile of students on average ranked their pilot skill higher than the other quartile's pilot skill rankings $(M=7.41, S D=0.59)$. The second and third quartiles each lowered their estimate of pilot skill successively $(M=7.04, S D=1.70$ and $M=6.74, S D=1.17$, respectively). The highest quartile only ranked their pilot skill on average at $7.25(S D=1.68)$.

When it came to estimating their score on the FAA exam, the bottom quartile overestimated their scores on average $(\mathrm{M}$ percentile $=68.4, \mathrm{t}(16)=9.775, \mathrm{p}<.0001)$. The middle two quartiles estimated the scores fairly accurately. However, the top quartile underestimated their scores on average $(\mathrm{M}$ percentile $=78.9, \mathrm{t}(15)=-5.644$, $\mathrm{p}<.0001)$.

\section{Discussion}

This study indicates that the Dunning-Kruger Effect is present in the SIUC aviation students. One must now ask how the awareness of the Dunning-Kruger Effect can be used to improve the educational process and safety.

Aviation is one of the few fields where education and safety can be a matter of mortal consequence. Being aware of the Dunning-Kruger Effect can help flight instructors to structure training sessions. One-size-fits-all training suboptimizes learning potential within a curriculum. Training sessions focusing more on basic flying skills should be developed for students with lower skills and higher confidence. Students with higher skills and lower confidence could be pushed and encouraged more, thus expanding their skills envelope. The difficulty would be in identifying in which group each student would be located. Flight instructors would need to take more time to more thoroughly evaluate each student, which in itself would be a good practice.

The Dunning-Kruger Effect can also help explain the high accident/fatality rate of general aviation pilots flying unfamiliar aircraft. Pilots might be over-confident with their ability and unaware of their limitations. By becoming aware of this phenomenon, pilots wanting to transition into a new type of airplane might be encouraged to seek additional training. At a minimum, the pilots may become more aware of the difficulties arising from transitioning into an unfamiliar aircraft and consequently focus more on their own abilities and limitations.

Every pilot, as well as any aviation professional making critical decisions affecting the safety of the NAS system (Air Traffic Controllers, etc.), needs to be aware of the Dunning-Kruger Effect. When facing a new and potentially dangerous situation, self-confidence is key, but overconfidence can be catastrophic. Self-awareness training, including psychological phenomena such as the DunningKruger Effect, should be part of any training curriculum.

\section{Conclusion}

Based on this study, the Dunning-Kruger Effect is prevalent in SIUC aviation students. The grammar exam utilized produced similar results to the Kruger and Dunning (2009) study at Cornell. In addition, overestimation of aviation specific knowledge capabilities on FAA knowledge exams may indicate a potential disconnect between perception and reality for SIUC aviation students. Future research should be conducted with flight students to determine if the Dunning-Kruger Effect is prevalent in flight skill performance. Other aviation disciplines should be investigated to determine the existence of the DunningKruger Effect

\section{Recommendations}

Due to the limitations of this study to students of one university aviation program, the next step is to expand the study to other aviation programs to be able to make a stronger argument for including psychological phenomena such as the Dunning-Kruger Effect in general pilot training curricula. Testing for the prevalence of the DunningKruger Effect in Air Traffic Controllers and other aviation 
professionals needs to be implemented. The biggest challenge will be to develop strategies to teach psychological self-awareness. Collegiate aviation curricula do a reasonable job of teaching students how to fly an airplane, or separate air traffic. Teaching an over-confident student about her or his limitations is more difficult, but critical to increasing the safety of the National Airspace System.

\section{References}

Alicke, M. D. (1985). Global self-evaluation as determined by the desirability and controllability of trait adjectives. Journal of Personality and Social Psychology, 49, 1621-1630, doi: 10.1037/0022-3514.49.6.1621.

Alicke, M. D., Klotz, M. L., Breitenbecher, D. L., Yurak, T. J., \& Vredenburg, D. S. (1995). Personal contact, individuation, and the better-than-average effect. Journal of Personality and Social Psychology, 68, 804-825, doi: 10.1037/0022-3514.68.5.804.

Allison, S. T., Messick, D. M., \& Goethals, G. R. (1989). On being better but not smarter than others: The Muhammad Ali effect. Social Cognition, 7, 275-296, doi: 10.1521/soco.1989.7.3.275.

Bobrow, J., Nathan, N., Fisher, S., Covino, W. A., Orton, P. Z., Bobrow, B., \& Weber, L. (1989). Cliffs NTE preparation guide. Lincoln, NE: Cliffs Notes, Inc.

Casner (2008) General aviation pilots' attitudes toward advanced cockpit systems, International Journal of Applied Aviation Studies, 8 (1), 88-112.
Codol, J. P. (1975). On the so called "superior conformity of the self" behavior: twenty experimental investigations. European Journal of Social Psychology, 5, 457-501, doi: 10.1002/ejsp.2420050404.

Cornell University Profile: class of 2015. (n.d.) Retrieved from http://dpb. cornell.edu/documents/1000001.pdf

Cross, P. (1977). Not can but will college teaching be improved? New Directions for Higher Education, 17, 1-15, doi: 10.1002/he. 36919771703.

Dunning, D., Meyerowitz, J. A., \& Holzberg, A. D. (1989). Ambiguity and self-evaluation: the role of idiosyncratic trait definitions in self-serving assessments of ability. Journal of Personality and Social Psychology, 57, 1082-1090, doi: 10.1037/0022-3514.57.6.1082.

Everson, H. T., \& Tobias, S. (1998). The ability to estimate knowledge and performance in college: A Metacognitive Analysis. Instructional Science, 26, 65-79, doi: 10.1023/A:1003040130125.

Grunhol, D. (2011) The Dunning-Kruger Effect in Aviation. Retrieved from http://www.eaa.org/lightplaneworld/articles/1002_dunning_ kruger.asp

Kruger, J., \& Dunning D. (2009). Unskilled and unaware of it: How difficulties in recognizing one's own incompetence lead to inflated self assessments. Journal of Personality and Social Psychology, 77 (6), 1121-1134, doi: 10.1037/0022-3514.77.6.1121.

Messick, D. M., Bloom, S., Boldizar, J. P., \& Samuelson, C. D. (1985). Why we are fairer than others. Journal of Experimental Social Psychology, 21, 480-500, doi: 10.1016/0022-1031(85) 90031-9. 